ORIGINAL ARTICLES

\title{
An interprofessional approach to promoting autonomous decision-making for clients who are aphasic
}

\author{
Jessie Johnson*1, Sarah Westgate ${ }^{2}$, Linda Oliver $^{3}$ \\ ${ }^{1}$ Faculty of Nursing, University of Calgary Qatar, Qatar \\ ${ }^{2}$ Ladysmith Community Health Centre, Island Health, BC, Canada \\ ${ }^{3}$ School of Nursing, Thompson Rivers University, Kamloops, BC, Canada
}

Received: April 9, 2019

DOI: $10.5430 /$ ijh.v5n2p44
Accepted: May 30, 2019

Online Published: June 11, 2019

URL: https://doi.org/10.5430/ijh.v5n2p44

\begin{abstract}
Often times interprofessional health care team members presume individuals with aphasia due to stroke lack the capacity to participate in and contribute to decision-making. This belief may hinder the client's participation in the decision-making process. Two main impairments resulting from stroke, that impede communication and limit capacity for autonomous participation in decision-making, are aphasia and cognitive deficits. Reduced capacity for communication in the client with stroke, combined with complexity in health team dialogue and process, may further diminish the individual's ability to engage in autonomous decision-making. Health team members need to use reliable methods and devise new methods which can more accurately measure capacity for autonomous decision-making. This review elucidates the necessity for (1) autonomous decision-making in persons with aphasia, (2) assessing the need for capacity, (3) concrete ways to assess cognitive function, and (4) interprofessional team decision-making.
\end{abstract}

Key Words: Inter-professional teams, Decision-making, Aphasia, Communication

\section{INTRODUCTION}

Stroke affects some 62,000 persons in Canada annually and is reported to be one of the most common causes of disability globally. ${ }^{[1]}$ In 2017, there were about 405,000 people living with the effects of stroke in Canada. ${ }^{[1]}$ Aphasia, as the result of stroke, occurs in $20 \%-40 \%$ of cases and presents challenges for stroke survivors, their significant others, and caregivers. ${ }^{[2]}$ Aphasia takes many different forms, some people are unable to speak, while others can speak but have difficulty in finding the right words. ${ }^{[3]}$ Aphasia results in "the loss of ability to communicate orally, through signs, or in writing, or the inability to understand such communications". ${ }^{[4]}$ Because of the effects of aphasia, stroke survivors may have difficulty understanding the most fundamental information. ${ }^{[5]}$ This can lead to an assumption by interprofessional team members and other caregivers that stroke survivors lack the ability to understand and contribute to decision-making. This assumption by interprofessional team members leads to the inability of the stroke survivor to assert autonomy for decision-making. ${ }^{[6,7]}$

*Correspondence: Jessie Johnson, PhD, RN; Email: Jessie.johnson1 @ ucalgary.ca; Address: Faculty of Nursing, University of Calgary Qatar, Qatar. 


\section{AUTONOMY AND INFORMED CONSENT IN} DECISION MAKING

Autonomy involves the right of the client to make decisions that are compatible with their personal choice for care. ${ }^{[8]}$ Although the capacity to enact autonomy may be preserved in some stroke survivors with aphasia, the ability to participate or fully engage in decision-making is often limited. ${ }^{[7]}$ Informed consent is a "consent which is obtained after the client has been adequately instructed about the ratio of risks and benefit involved in the procedure as compared to alternative procedures or no treatment at all". ${ }^{[9]}$ The client who can not achieve informed consent, or who is unable to display the existence of capacity for informed consent, may suffer adverse effects to health and well-being. When an individual can not clearly advocate for his or herself, health care interventions may be delayed or less than optimum for that individual. Autonomy may be violated and the client may experience a negative impact on mood and well-being. Clients who are unable to provide consent may experience delayed or inadequate access to medical services and risks therein include, negative impact on mood, loss of independence, decreased access to cognitive rehabilitation, increased risk of falls and decreased medication compliance, decreased ability for future chronic disease self-management, poor health outcomes and increased risk of long-term care placement. The individual may suffer from self isolation and institutionalization. Prolonged health care may ensue, compounding economic costs to the health care system. To reduce the potential for these adverse outcomes, interprofessional team members must adopt a collaborative approach which strives to promote a client's ability to enact autonomy. Determining an individual's capacity for autonomous decision making is part of a collaborative approach needed in order to gain informed consent for health care services. ${ }^{[10]}$

\section{INTERPROFESSIONAL TEAM COLLAB- ORATION TO PROMOTE AUTONOMOUS DECISION-MAKING}

Collegial relationships with interprofessional teams in stroke management and decision-making are not meant to be paternalistic where health care professionals make decisions on behalf of the stoke survivor with aphasia. ${ }^{[11]}$ At the heart of every interdisciplinary team is the person with aphasia and every decision should be construed as a reciprocal partnership. ${ }^{[12]}$ Health care team members should consider stroke survivors' autonomy and the right to make decisions, thus supporting communication during the decision-making process. ${ }^{[13]}$ Some individuals with aphasia will rely on family members to create the link between themselves and the interprofessional team, yet this can also be seen as a barrier

Published by Sciedu Press if clients resist this mode of communication. ${ }^{[14]}$ Effective communication with clients with aphasia will depend on contributions offered from different perspectives, these include those of physicians nurses, physicians, pharmacist and social workers. Due to the physical and cognitive complexity that is a direct result of a stroke, no one single discipline is able to manage the trajectory of the rehabilitation alone. ${ }^{[15]}$

Different team members interact with the client in different ways and contexts, and each member has potential to contribute meaningful observations, as well as to promote effective communication for and with the client. Interdisciplinary teams are pivotal in the negotiations of decision-making for persons with aphasia. ${ }^{[11]}$ Decision-making should be carried out utilizing an interprofessional collaborative approach and should be done with the full participation of the stroke survivor or surrogate decision-maker. Stroke survivors ultimately determine the course of their rehabilitation since goals must fit their personal qualities and lifestyle experienced before the stroke, as well as their circumstances following the stroke. ${ }^{[11]}$ A person with aphasia has the right to self-determination in decision-making and that right should be promoted and respected by all members of the interprofessional team. ${ }^{[16]}$ In order for that right to be enacted and respected, the interprofessional team members must accurately determine an individual's capacity for decision making.

\section{Assessing CAPACITy IN PERSONS With APHASIA}

A capable adult, with the capacity to enact autonomy and give informed consent, is one who demonstrates an understanding of the proposed treatment, the risks and benefits, the condition for which it is proposed and alternatives and that it applies to their own situation. ${ }^{[17]}$ Cognition can be defined as processes in the mind that produce thought and goal-directed action. ${ }^{[18]}$ The mental capacity to formulate goals, create task-specific plans, and execute and complete these plans can be described as executive functions. ${ }^{[19]}$ Thus, executive functioning is necessary to both goal setting and task execution. ${ }^{[20]}$ The "impairment or loss of [executive] ... functions compromises a person's capacity to maintain an independent, constructively self-serving, and socially productive life". ${ }^{[19]}$

Cognition and executive functioning are central to capacity for autonomous decision-making as both determine and are used to demonstrate the person's capacity to make decisions by identifying a goal and following through on intentions and monitoring oneself to ensure a successful outcome. Assessment of executive functioning gives valuable information to the interprofessional team, with insight about a person's ability to participate in the decision making that influences 
the course of a person's rehabilitation. ${ }^{[7]}$ Cognition and executive functioning are also important in developing a daily rehabilitation program for stroke victims with aphasia. As part of the interdisciplinary team, Occupational Therapists (OTs) routinely assess cognition in older adults. ${ }^{[6]}$ The OT can assist the interprofessional team in early identification of individuals with aphasia who cannot verbalize consent, and in assessing individuals with cognitive challenges who require support with decision-making though assessment of cognition and specifically executive functioning. The OT can contribute significant information about a client's capacity for autonomous decision-making. OTs routinely assess cognition in older adults. ${ }^{[6]}$ Assessment of cognition is necessary prior to therapies which are aimed at developing ongoing participation in meaningful activities of daily life for example; self-care skills, education, work or social interaction, especially to uplift and inspire participation in such activities despite impairments and limitations in physical or mental functioning. ${ }^{[21]}$

The challenge for health care professionals in regard to assessing aphasic clients is well established. Nurses are poised to observe client's ability to manage complex tasks associated with activities of daily life and can provide indicators of capacity for informed consent. Observable or measurable indicators such as participation in Instrumental Activities of Daily Living (IADL) and ADLs can be indicators of cognition and executive functions, because an individual's performance on these type of daily tasks require initiation, planning, self-monitoring and correcting for successful completion. These measures of capacity can be critical for deciding how, and whether, interprofessional teams can gain informed consent needed for health care interventions.

Many common cognitive screening assessments which might normally be utilized by interprofessional teams to screen for cognitive impairment and executive dysfunction, such as the Montreal Cognitive Assessment (MoCA) have sections that rely upon verbal interactions. However, reliance on verbal interactions and verbal communication abilities would not typically be helpful in attempting to determine capacity or assess executive functioning for a client with aphasia. Nor would it be helpful in attempting to determine capacity for informed decision making in a client with aphasia. ${ }^{[22,23]}$

Assessment of capacity in individuals can be made by interprofessional team members such as occupational therapists using standardized and non-standardized assessments. The benefit of using standardized assessments in a clinical setting to assess cognition in an individual are many. Standardized tests are characterized by consistent administration and scoring processes and psychometric data is available in regards to validity and reliability of standardized assessments, making these tools useful in objectively measuring performance. ${ }^{[24]}$ Non-standardized assessments by skilled clinicians may also inform interprofessional teams and contribute to team-based assessments in assessing capacity for decision making.

In consideration which tests and measures to choose when working with an individual with aphasia, two appropriate standardized tests utilized by occupational therapists include the Executive Function Performance Test (EFPT) ${ }^{[20]}$ and the Kettle Test. ${ }^{[25]}$ These tests can be administered in hospital or community settings provided appropriate space and materials is available and both do not rely upon verbal responses. These tests require the person to perform four activities of daily living. These activities could be such things as making a piece of toast, using the phone, paying a bill or self administration of medication and or observation of the preparation of a hot beverage. ${ }^{[20,25]}$ These test are pivotal in the assessment of decision-making and the ability to live independently. Where the tools or environment preclude the use of these, non-standardized functional assessments may also be employed though this approach cannot be relied upon to measure change in client performance, for instance, in the same way that standardized tests may. While changes in cognitive function are not always readily apparent in a hospital ward setting where little cognitive demand is placed on the individual. ${ }^{[26]}$ OTs may still use skilled observation as a non-standardized assessment method to analyze and interpret occupational performance of daily tasks in any setting. ${ }^{[26]}$ Other team members, such as nursing staff who care for clients on a daily basis, may also have key observations which can contribute to assessment of client capacity. By sharing skilled observation, the team will gain information which will be useful in determining cognitive and executive functioning and capacity for decision making. Indeed, a varied approach including diverse assessment and gaining collateral information is most appropriate when assessing different cognitive domains. ${ }^{[27]}$ Multiple and diverse tools and approaches should be done to gain the most comprehensive assessment of the person with aphasia, and this includes the diverse skills of an interprofessional team.

\section{WHEN COMPETENCY CAN NOT BE DEMONSTRATED}

Despite the best efforts of the interprofessional team, situations exist where competency may not be clearly established for individuals with aphasia. A surrogate decision make will be needed. A desirable surrogate decision maker is one who is able and willing to be an informed and responsible decision maker; and who has a relationship with the adult that makes the person an appropriate choice. The surrogate 
decision maker's responsibility is to represent the instructions or wishes expressed by the adult when capable and if not known, to act in the best interests of the adult for whom they are giving or refusing informed consent. ${ }^{[28]}$ Should surrogate decision-making become the best option for the client with aphasia, a collaborative interdisciplinary team approach must continue. The goal of meeting the unique individualized needs of the client remain the same.

\section{Conclusion}

Individual survivors of stroke suffering from aphasia may be unable to demonstrate the capacity to enact their right of autonomy with decision-making. Multiple adverse outcomes may ensue when clients can not participate in decisions affecting their care. Lack of capacity for autonomy must not be assumed to exist. Rather, it is the duty of the interprofessional team to determine a client's capacity for autonomy and if it is determined to be present, it is their duty to assist the client to enact that capacity. Capacity for autonomy can be determined by use of a variety of standardized and nonstandardized assessment tools. The Occupational therapist is in a unique position to assist in determining autonomy due to their expertise in assessing cognition and how it relates to an individual's capacity for decision making.
When capacity for autonomy can not be demonstrated, a surrogate decision maker must be found. In all cases, the client's multiple needs will be served best by a collaborative, interprofessional approach.

\section{Recommendations}

An interprofessional approach to assessment and treatment is beneficial to members of the healthcare team and the aphasic clients. Family members may be involved to assist people with aphasia navigate access to health care. However, every effort must be made to involve clients in decision-making including assessing their executive functioning and supporting them as necessary to make informed decisions in the course of their care. Although all members of the healthcare team play a vital role in assessing persons with aphasia in a variety of areas, OT's provide a unique contribution to interprofessional teams because of their expertise in assessing for executive function and decision-making capacity. A variety of standardized and informal performance-based assessments are appropriate and may be used by occupational therapists to assess executive functioning in aphasic clients.

\section{CONFLICTS OF INTEREST Disclosure}

The authors declare no conflicts of interest.

\section{REFERENCES}

[1] Canadian Best Practice Stroke Report. Different strokes, recovery triumphs and challenges at any age 1-16. 2017.

[2] Teasell R, Meyer M, Foley N, et al. Stroke rehabilitation in Canada: A work in progress. Topics in Stroke Rehabilitation. 2009; 16: 11-19. PMid:19443343. https://doi.org/10.1310/tsr1601-11

[3] Maas MB, Lev MH, Ay H, et al. The prognosis for aphasia in stroke. J. Stroke Cerebrovasc. Dis. 2012; 21: 350-357. PMid:21185744. https://doi.org/10.1016/j.jstrokecereb rovasdis. 2010.09.009

[4] Cotoi A, Salter K, Jinah A, et al. Aphasia and Apraxia in Evidence Based Reviews of Stroke Rehabilitation Chapter 14, 1-77. 2016.

[5] Geurts M, Macleod MR, van Thiel GJ, et al. End-of-life decisions in clients with severe acute brain injury. Lancet Neurology. 2014; 13: 515-24. https://doi.org/10.1016/S1474-4422(14)700 $30-4$

[6] Pachet A, Allan L, Erskine L. Assessment of fluctuating decisionmaking capacity in individuals with communication barriers: A case study. Topics in Stroke Rehabilitation. 2012; 19: 75-85. PMid:22306631. https://doi.org/10.1310/tsr1901-75

[7] Suleman S, Hopper T. Decision making capacity in aphasia: Speechlanguage pathologistsperspectives. Aphasiology. 2016; 30: 1-15. https://doi.org/10.1080/02687038.2015.1065468

[8] Vioxx. (n.d.) McGraw-Hill Concise Dictionary of Modern Medicine. 2019. Available from: https://medical-dictionary.thefre edictionary.com/Vioxx

Published by Sciedu Press
[9] Herbert V. Informed consent - a legal evaluation. Cancer. 1980; 46(4): 1042-1043. https://doi.org/10.1002/1097-0142(19800815 ) 46:4+<1042: :AID-CNCR2820461330>3.0.CO;2-E

[10] Care (Consent) and Care Facility (Admission) Act 1996, c.181. Available from: http://www.bclaws.ca/civix/document/id/co mplete/statreg/96181_01\#section7 (Accessed: 22 July 2018)

[11] Johnson J. Interprofessional team collaboration in stroke survivor care: A review of the literature. Perspectives Journal. 2015; 38(2): 20-23.

[12] National Stroke Foundation. Clinical guidelines for stroke management 2010. Melbourne.

[13] Barry MJ, Edgman-Levitan S. Shared decision-making: The Pinnacle of Client Centered Care. New England Journal of Medicine. 2012; 366: 780-781. PMid:22375967. https://doi .org/10.1056/NE JMp1109283

[14] Laidsaar-Powell R, Butow P, Bu S, et al. Physician-client-companion communication and decision-making: A systematic review of trials in medical consultations. Client Education and Counseling. 2013; 91: 3-13. PMid:23332193. https://doi.org/10.1016/j.pec. 2012.11.007

[15] Purvis T, Bernhardt J, Indredavik B, et al. Interdisciplinary team interactions in stroke units: Can team dynamics influence client outcomes from a clinician's perspective. International Journal of Physical Medicine \& Rehabilitation. 2014; S3: 007. https ://doi . org/10.4172/2329-9096.S3-007

[16] Beauchamp TL, Childress JF. Principles of biomedical ethics. New York: Oxford University Press; Chapter 4. 2013. 
[17] Vancouver Coastal Health and Providence Health, Re:Act Client Protection Program (2013). Consent and Capability Guide BC Edition. Available from: https://vch.eduhealth.ca/PDFs/IB/IB . 10 0.C33.pdf (Accessed: 22 July 2018)

[18] Trombly C, Radomski M, Trexel C, et al. Occupational therapy and achievement of self-identified goals by adults with acquired brain injury: Phase 11. American Journal of Occupational Therapy. 2002; 56(5): 489-498. PMid:12269503. https ://doi .org/10.5014/aj ot .56 .5 .489

[19] Lezak M. The Problem of Assessing Executive Functions. International Journal of Psychology. 1982; 17: 281-297. https ://doi.or $\mathrm{g} / 10.1080 / 00207598208247445$

[20] Baum C, Connor L, et al. Reliability, validity and clinical utility of the executive function performance test: A measure of executive function in a sample of people with stroke. The American Journal of Occupational Therapy. 2008; 62(4): 446. PMid:18712007. https://doi.org/10.5014/ajot.62.4.446

[21] Mariam Webster collegiate dictionary. Springfield Massachusetts, USA: Mariam Webster, Incorporated, 2018.

[22] Nasreddine ZS, Phillips NA, Bedirian V, et al. The Montreal Cognitive Assessment, MoCA: A brief screening tool for mild cognitive impairment. Journal of the American Geriatrics Society. 2005; 53 696-699. PMid:15817019. https://doi.org/10.1111/j.1532 $-5415.2005 .53221 . \mathrm{x}$
[23] Kurlowiez L, Wallace M. The Mini Mental State Examination (MMSE). Hartford institute for Geriatric Nursing (3). 1999.

[24] Unsworth C. Reflections on the Process of Therapy. In Unsworth, C. Cognitive and Perceptual Dysfunction: A Clinical Reasoning Approach to Evaluation and Intervention (pp. 75 to 124). Philadelphia: FA Davis Company. 1999.

[25] Hartman-Maeir A, Harel H, Katz N. Kettle test - a brief measure of cognitive functional performance. Reliability and validly in stroke rehabilitation. American Journal of Occupational Therapy. 2009; 63(5): 592-599. PMid:19785258. https://doi.org/10.5014/ajot.6 3.5 .592

[26] Bisiker J, Bickerton W. Using a comprehensive and standardized cognitive screen to guide cognitive rehabilitation in stroke. British Journal of Occupational Therapy. 2013; 76(3): 152-156. https : //doi.org/10.4276/030802213X13627524435261

[27] Hirsch O, Rohrie B. Association Between Self-Assessed Attention and Objective Neuropsychological Tests in Parkinson Disease. 2011; 24(2): 68-73. PMid:21697709. https : //doi .org/10.1097/WNN . Ob013e3182274e7a

[28] Public Guardian Trustee of British Columbia. Information for Public Guardian and Trustee Substitute Temporary Decision Makers Authorized by the Public Guardian and Trustee. 2015. Available from: www.trustee.bc.ca 